\title{
Research on Sustainability of University-Enterprise Cooperation Mode for Excellent Engineer Training
}

\author{
Zhaolin Liu' ${ }^{1, a}$, Yifang Zhang ${ }^{1, b}$ \\ ${ }^{1}$ College of Textile and Garment, Hebei University of Science and Technology, Shijiazhuang 050018, \\ China. \\ aliuzhaolin0508@163.com, b1142237071@qq.com
}

Keywords: excellent engineer training, university-enterprise cooperation mode, sustainable development, long-term mechanism.

\begin{abstract}
The sustainable development of university-enterprise cooperation for excellent engineer training is the critical factor influencing the success of higher-level engineering talent cultivation. Both the university and the enterprise should follow the market rule and the education law according to the demand of social development. Taking the enterprise profit, school development, student growth and all-win as the goal, we should explore more improved cooperation training mode actively, stick to optimizing the training scheme and promoting the connotation construction of excellent engineer training, so as to establish the long-term mechanism of univeristy-enterprise cooperation.
\end{abstract}

\section{Introduction}

In the year 2011, the Ministry of Education proposed that the implementation of "excellence program" should follow the principles of "industry guidance, university-enterprise cooperation, classified implementation, diversified forms and pursuit of excellence", with the participation of enterprises as the precondition for "excellence program" implementation [1]. This shows that the close cooperation between education and industry, university and enterprise becomes the key to success of “excellence program”.

Basically speaking, implementation of "excellence program” is ultimately aimed at realizing all-win of enterprise, university and student. Whether this objective can be realized directly affects the future development of university-enterprise cooperation training mode. For training of excellent engineers, the demand of enterprises should be taken as guidance, the engineering practice should be takend as background, and engineering technology is the main line. Universities and enterprises cooperate closely to prepare talent training standard, reform talent training mode, build the engineering education teaching staff with high level, open wider to the outside world, and focus on improving the engineering qualities of students as well as cultivating the engineering practice ability, design capability and innovation ability of students [2]. Therefore, the reform of talent training mode and the strengthening of university-enterprise cooperation is the core of "excellence program".

\section{Innovation of University-Enterprise Cooperation Training Mode for Excellent Engineers}

\section{Characteristics of Current University-Enterprise Cooperation Training Mode.}

Currently, there are four types of univeristy-enterprise cooperation training modes including order type, "sandwich" type, project cooperation and co-establishment of training bases. The order type means that the employers put forward the standard, quantity and training period of talent demand. Then the universities cultivate the talents in accordance with the training agreement signed by universities and enterprises [3]. The "sandwich" type divides the training process of talents into three stages. The first stage is maily about theory learning in university, the second stage is specialty practice in enterprise, and the third stage is specialty learning in univerisity. The "sandwich" type follows the "learning-practice-learning again" educational pattern [4]. Project cooperation type takes the project as carrier and the university-enterprise win-win as the goal, students are cultivated during the project cooperation of university and enterprise [5]. Co-establishment of training bases means 
that the universities and the enterprises build the education and production bases which can meet not only the practical teaching requirement of universities, but also satisfy the production need of enterprises [6].

However, the order type is adverse for long-term development of enterprises and the educational property of universities is weakened. In "sandwich" type, universities and enterprises conduct single training independently, so resource integration is at low level. Moreover, Students have difficulty in adapting the frequent change of their roles and the enviroment. Project cooperation is often temporary and random, which is not helpful for comprehensive training of students. As for the co-establishment of training bases, the slow renewal of equipment can not meet the practice requirements of advanced technology.

Establishment of the "Three Dimensional” University-Enterprise Cooperation Training Mode. "Three dimensional” training mode refers to a new type of university-enterprise cooperation training mode, under which enterprises involved in the cultivation of excellent engineers in all round, whole process and deep level way. On one hand, enterprises are required to participate in the whole process of excellent engineer training. This process should start from the cultivation of students' professional perceptual knowledge when they enter the school. This process should run through all terms and academic years for training excellent talents, and end with the completion of professional and rational cognitive training when students graduate. On the other hand, enterprises should participate in all levels of excellent engineer training. There are four levels concerning excellent engineer training, namely learning of theoretical knowledge, exercise of practical abilities, development of scientific research abilities and cultivation of innovative spirit. It can be seen that these levels depend on each other, and move forward step by step. All round participation means that the enterprise should participate in all sections of excellent engineer training, which include formulation and implementation of training plan, construction of teaching staff, reform of curriculum system and teaching contents, research on teaching methods, guidance on graduation design and thesis, evaluation of the talents training quality and other sections. "Three dimensional" training mode makes the university-enterprise cooperation training change from two independent training parts into a unified whole.

Base on the premise of mutual benefit and a win-win situation, universities and enterprises give full play to their respective advantages in cultivating excellent engineers, and share responsibilities and obligations of excellent engineer training. Only in this way, can the long-term development needs of enterprises, universities and students be better met.

\section{Construction of Sustainable Enterprise Training Program for Excellent Engineers}

Whether the enterprise training scheme is scientific and reasonable is an important foundation for the cultivation of excellent engineers. It is also an important factor influencing whether the enterprise can eventually earn profit, and even a critical factor concerning whether the excellence program can be realized successfully.

\section{Accurate Orientation of the Enterprise Training Targets.}

Universities joining in the "excellence program” have two important features. Firstly, the types of universities are different, including research type, research-teaching type, teaching-research type, teaching type and so on. Different university types lead to different levels of talent training. Secondly, the service objects of universities are also different. Some universities face the whole nation, some face provinces, autonomous regions or municipalities, and others face the local area. Therefore, when enterprises participate in the "excellence program", they should put the accurate orientation of training targets in the first place.

On the one hand, the orientation of enterprise training targets should meet the requirements of "excellence program" for the excellent engineer training. On the other hand, the training targets should meet the actual conditions and development needs of the enterprises, too. Enterprises in different development stages have different training capacities and development needs. Small and medium enterprises are restricted by enterprise scale, capital turnover and production technology, 
they mainly pursue short-term benefits and hope the university-enterprise cooperation training is short, smooth and quick. Therefore, their training targets are usually positioned in production-oriented and service-oriented excellent engineers. Large enterprises have abundant capitals and are more inclined to long-term training mode with high return. Therefore, they generally need design-oriented and research and development type engineers. All in all, accurate position of the training targets can point out the direction for the construction of enterprise training programs.

\section{Reasonable Formulation of the Enterprise Training Standards.}

Enterprise training standards are core contents of enterprise training scheme, and programmatic documents leading enterprises launching excellent engineers training. First, actual situation, development requirements and industrial characteristics of enterprises should be closely integrated in the preparation of enterprise training standards, and the enterprise training targets should be met. Second, enterprise training standards should also meet general requirements of the training standards for excellent engineers and talent standard requirements of the industry that an enterprise belongs to. Training standards for excellent engineers are raised by the state and are the basic requirements for training of all kinds of excellent engineers in each industry. Industrial talent standards represente the basis level that excellent engineers in each industry should reach. They not only reflect the specialized characteristics and industrial requirements, but also a specific embodiment of the training standards for excellent engineers. Finally, training standards of the enterprises should be in consistent to those of the universities. Universities and enterprises should try to accomplish the knowledge training standards, ability training standards and quality training standards by means of concrete course teaching and practical links.

\section{Scientific Establishment of the Enterprise Cultivation System.}

Establishment of the enterprise cultivation system should follow the principles of overall design and specific goals. The system is not a simple reproduction of traditional university-enterprise cultivation mode, and cannot be the combination of various practices of students in enterprises. It should be designed according to training objectives and standards collectively prepared by universities and enterprises. Meanwhile, the actual situations of the enterprises should be taken into consideration. During the design process, training objectives are broken down into several detail training requirements level by level, thus forming perfect training system. The cultivation activities that enterprises can participate in mainly include course lecture, spot teaching, professional practice, graduation design, special report and technological innovation.

\section{Dynamic Implementation of Enterprise Training Program for Excellent Engineers}

Preparation of enterprise training program is not once for all. It should be constantly optimized according to the actual effect of excellent engineers training, the improvement of the cultivation standards, and the demands of various kinds of excellent engineers during enterprise development. Therefore, the enterprises must conduct development assessment and evaluate the talent training quality constantly in the process of training program implementation. As a result, the sustainable development of the enterprises and the successful cultivation of excellent engineers can be always in a good and persistent state. This is the so-called dynamic implementation process.

Enterprise mentors are mainly responsible for the dynamic implementation of enterprise training program, and full-time teachers in universities offer assistance. The implementation process includes three important links. First, enterprises should establish perfect business assessment mechanism and talent training evaluation mechanism. Only enterprises accurately carry out market positioning and obtain objective talent training results, can subsequent training program adjustment be meaningful. Second, enterprises should subdivide the training objectives carefully and determine cultivation standards for each segment, so as to make the adjustment of the training program more specific and focused. Finally, enterprises should pay enough attention to process management, summarize and improve the training program in time to make the training process of excellent engineers in good controll. 


\begin{abstract}
Summary
"Program of Educating and Training Excellent Engineers" is a major education reform project of higher engineering education meeting national strategic demands, enterprise needs of active service and establishment of university-enterprise co-cultivation mechanism, so as to fundamentally solve university-enterprise disconnection problem in higher engineering talent training. Based on analysis of the connotation of sustainable university-enterprise cooperation training of excellent engineers and the disadvantages of the current cooperation training modes, this paper raises the new "three-dimensional" university-enterprise cooperation training mode, namely the enterprises should participate in the whole process of excellent engineers cultivation in deep level and in all round. Then we explain the working methods of how to scientific prepare and dynamic implement the enterprise training program. As a result, the long-term mechanism of university-enterprise cooperation training for excellent engineers is established.
\end{abstract}

\title{
Acknowledgement
}

This work was financially supported by the Social Science Fund of Hebei Province (HB16JY035).

\section{References}

[1] J. Lin, The whole cooperation process between universities and enterprises on training ourstanding engineers, Higher Engineering Education Research. 3 (2012) 7-23. (in Chinese)

[2] J. Lin, On the professional training program of "a plan for educating and training outstanding engineers”, Qinghua Journal of Education. 2 (2011) 47-55. (in Chinese)

[3] H.C. Wang, L.J. Jiang, Enlightening of home and international college-enterprise cooperation on "program of educating and training excellent engineers" in China, Journal of Huaihai Institute of Technology. 8 (2010) 14-16. (in Chinese)

[4] D. Tjosvold, S.L. Kenneth and S. Haifa, Effectiveness of Chinese teams: the role of conflict types and conflict management approaches, Management and Organization Review. 2 (2006) 231-252.

[5] Z.G. Yang, J. L. Qian, Construction of practice teaching system for automation professional excellent engineers training plan, The Guide of Science and Education. 11 (2015) 27-28. (in Chinese)

[6] A. Wang, D. Tjosvold and Z.Y. Yu, Organizational partnerships in China: self-interest, goal, interdependence and opportunism, Journal of Applied Psychology. 4 (2005) 782-791. 